\title{
Influence of solution treatment on microstructure, corrosion resistance, and oxidation behavior of cast G-NiCr28W alloy
}

\author{
*Alptekin Kisasoz \\ Yildiz Technical University, Department of Metallurgical and Materials Engineering, Davutpasa Campus, TR34210, Esenler, \\ Istanbul, Turkey
}

\begin{abstract}
G-NiCr28W is a nickel-based cast alloy. Its microstructure consists of nickel-rich matrix phase and chromium-rich eutectic carbides. The solution treatment process can provide homogenous microstructure and desired mechanical/thermal properties for G-NiCr28W alloy. However, the solution treatment process affects the corrosion resistance of the alloy and it causes metal loss due to the occurrence of oxidation at atmospheric conditions. Therefore, determining the changes in the properties of the $\mathrm{G}-\mathrm{NiCr} 28 \mathrm{~W}$ is important. For this purpose, G-NiCr28W specimens were solution treated at $1,040{ }^{\circ} \mathrm{C}, 1,100{ }^{\circ} \mathrm{C}$ and $1,160{ }^{\circ} \mathrm{C}$ for $1 \mathrm{~h}$ and $8 \mathrm{~h}$, respectively. The microstructures of the solution-treated samples were characterized by optical microscopy, scanning electron microscopy, energy dispersive spectroscopy and X-ray diffraction analysis. Moreover, hardness, corrosion resistance and oxidation behaviors of the solution-treated samples were examined. The solution treatment process applied at $1,160{ }^{\circ} \mathrm{C}$ led to the formation of $\mathrm{Fe}_{2} \mathrm{~W}_{2} \mathrm{C}$ blocky carbides, and hardness of the sample increased with the existence of blocky carbides, while corrosion resistance decreased. Furthermore, excessive metal loss occurred depending on oxidation due to the high process temperature at $1,160{ }^{\circ} \mathrm{C}$.
\end{abstract}

Key words: G-NiCr28W; nickel-based alloy; heat treatment; corrosion behaviour; oxidation

CLC numbers: TG132.3 3 Document code: A

Article ID: 1672-6421(2019)01-063-08

$\mathrm{N}$ ickel based alloys (NAs) have a rather higher melting point comparing to other widely used alloys. Also, the NAs have higher mechanical properties as well as oxidation resistance at elevated temperatures with the face-centered cubic (FCC) matrix and existing carbides. Therefore, NAs are widely used in high temperature structural applications. Generally, the NAs contain chromium, tungsten, niobium and titanium as carbide forming elements and $\mathrm{M}_{7} \mathrm{C}_{3}, \mathrm{M}_{6} \mathrm{C}, \mathrm{MC}$ carbides are formed depending on thermal exposure during the manufacturing process. G-NiCr28W is one of the most used alloys in heat treatment plants among the NAs ${ }^{[1-4]}$. G-NiCr28W contains relatively higher carbon and chromium, and lower tungsten than typical NAs. Increasing the amount of carbon in NAs to above $0.2 \%$ makes the formation

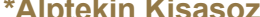

Male, born in 1985, Ph.D, Research Assistant at Yildiz Technical University Department of Metallurgical and Materials Engineering since 2009. He is currently working on the heat treatment and welding metallurgy of duplex stainless steels and nickel-based alloys.

E-mail: akisasoz@yildiz.edu.tr of carbide in the structure inevitable. Accordingly, the microstructure of the G-NiCr28W alloy consists of eutectic carbides and FCC matrix ${ }^{[5-10]}$.

Formation of the solid solution with tungsten, chromium, molybdenum is the main strengthening mechanism for the NAs. These alloying elements can lead to the formation of carbides like $\mathrm{M}_{23} \mathrm{C}_{6}, \mathrm{M}_{6} \mathrm{C}$ and $\mathrm{MC}$ as mentioned before, especially for $\mathrm{G}-\mathrm{NiCr} 28 \mathrm{~W}$, whose microstructure is composed of chromium based eutectic carbides and solid solute FCC austenite phase ${ }^{[11-15]}$. Thus, solution treatment is applied to the NAs for refining the carbide structures and to obtain a homogenous microstructure. Zengwu T et al ${ }^{[16]}$ investigated the effect of solution treatment on nickelchromium-tungsten based samples in order to evaluate the changes in carbide structure. Solution treatment procedures were conducted between $1,230-1,300{ }^{\circ} \mathrm{C}$ for 10 to $120 \mathrm{~min}$, and the type and morphology of the carbides were investigated for different samples. It was determined that the volume fraction of the carbides decreased with increasing solution treatment temperature depending on the dissolution of the carbide structures in the $\gamma$ matrix phase. Rodriquez $\mathrm{J}$ 
et al ${ }^{[17]}$ studied the ageing of cast nickel-based heat-resistant alloy at relatively lower temperatures, and experimental results indicated that primary carbides dissolved in the $\gamma$ matrix also in this work. Sun et al ${ }^{[18]}$ showed that the intragranular carbides are more prone to dissolution compared to the intergranular carbides. Element diffusion towards the grain boundaries is faster and thus, the intergranular carbides show higher growth kinetics.

Although the NAs show high oxidation resistance, one of the main problems occurring during the solution treatment is still oxidation. According to Haugsrud ${ }^{[19]}$, the oxidation mechanism of nickel is quite complex and not fully clear. The oxide layer formed on the surface of specimens is in the form of $(\mathrm{Fe}, \mathrm{Ni}) \mathrm{O} /(\mathrm{Fe}, \mathrm{Cr})_{2} \mathrm{O}_{3}$ for nickel-chromium-iron ternary system. At this type of oxide, the proportion of the mass of metal to oxygen is 2.6. The weight gain in the samples implies oxygen mass in the formed oxide. Thus, the value of weight gain should be multiplied by 2.6 to determine the metal loss during the oxidation process. Svistunova et al ${ }^{[20]}$ studied the oxidation behaviour of nickel-chromium-iron based alloys in the $\mathrm{Ni}-20 \% \mathrm{Cr}$ system with the existence of iron. The metal loss during the oxidation process was determined by multiplying the weight gain with 2.6 and the results showed that increasing the process temperature from $1,100{ }^{\circ} \mathrm{C}$ to $1,200{ }^{\circ} \mathrm{C}$ significantly accelerated the oxidation. In addition, the high-temperature oxidation behaviour of Haynes 282 superalloy was studied under various oxygen partial pressures by Perez-Gonzalez et al ${ }^{[21]}$. According to the experimental investigations, oxidation of nickel-based alloys is sensitive to the changes in oxygen partial pressure values during the heat treatment process. However, experimental studies about the microstructural variations during the solution treatment of the G-NiCr28W are rather limited.

Another important consideration is that the variation of corrosion resistance of the NAs depends on the morphological properties. Precipitation of the carbide structures during solidification affects the corrosion properties of the NAs. The solution treatment is usually applied to provide proper morphological properties. However, precipitation of carbides is inevitable for nickel-chromium-iron alloys with carbon contents greater than $0.2 \%{ }^{[22-25]}$. Thus, determination of corrosion behaviour of the NAs after the solution treatment is essential.

In this work, microstructural changes in the G-NiCr28W during the solution treatments were evaluated and also, oxidation and corrosion behaviours of the G-NiCr28W were investigated. Microstructural properties of the samples were investigated by the optical microscopy (OM), scanning electron microscopy (SEM), energy dispersive spectroscopy (EDS) and X-ray diffraction (XRD) analysis. Moreover, the relationship between microstructure and mechanical properties were evaluated with Vickers hardness (HV) tests. Corrosion behaviour of the samples was determined by potentiodynamic polarization tests.

\section{Material and methods}

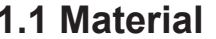

The material used in experimental studies was G-NiCr28W alloy, with a chemical composition (wt.\%) of Cr 27.35, Fe 13.75, W 4.82, Mo 0.21, C 0.53, Si 1.22, Mn 0.90, S 0.02, P 0.03 and balanced by $\mathrm{Ni}$. A cast specimen was cut out and the samples with the dimensions of $10 \mathrm{~mm}$ in height, $10 \mathrm{~mm}$ in wide and 5 $\mathrm{mm}$ in depth were obtained. The samples were ground up to 2000 grit $\mathrm{SiC}$ paper and polished with $1 \mu \mathrm{m}$ diamond paste following the cutting process for determining accurate metal loss value due to oxidation during solution treatments.

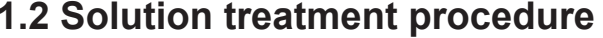

The microstructure of the G-NiCr28W alloys consisted of FCC matrix and eutectic carbides. In order to refine microstructure of the $\mathrm{G}-\mathrm{NiCr} 28 \mathrm{~W}$, the solution treatment process was applied at $1,040{ }^{\circ} \mathrm{C}, 1,100{ }^{\circ} \mathrm{C}$ and $1,160{ }^{\circ} \mathrm{C}$ for $1 \mathrm{~h}$ and $8 \mathrm{~h}$, followed by water quenching to provide desirable microstructure. The solution-treated samples were classified as shown in Table 1.

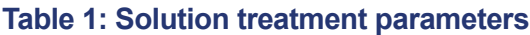

\begin{tabular}{ccc}
\hline S1 & $\begin{array}{c}\text { temperature }\left({ }^{\circ} \mathbf{C}\right) \\
\text { duration (h) }\end{array}$ \\
S2 & 1,040 & 1 \\
S3 & 1,040 & 8 \\
S4 & 1,100 & 1 \\
S5 & 1,100 & 8 \\
S6 & 1,160 & 1 \\
\hline
\end{tabular}

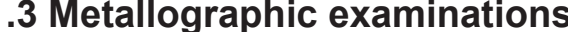

Solution-treated samples were prepared with standard grinding and polishing techniques. Electrolytic etching was applied in 1\% $\mathrm{NaOH}$ solution with $2.5 \mathrm{~V}$ potential to reveal microstructures. Cross-sectional microstructures of the annealed specimens were taken using an optical microscope (OM) (Nikon Eclipse MA100) and a scanning electron microscope (SEM) (Zeiss EVO LS10). Energy dispersive spectroscopy (EDS) analysis was performed to attain elemental content in specific spots.

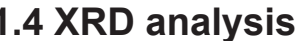

XRD analysis was carried out to determine the carbide transformation depending on the solution treatment temperature and time. For this purpose, XRD analysis was applied to all samples. Formed phases were identified by Philips PW 3710 using $\mathrm{CuK} \alpha$ radiation over a $2 \theta$ range of $30^{\circ}-90^{\circ}$.

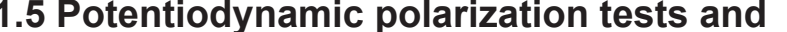

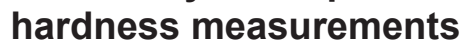

Potentiodynamic polarization tests were performed in 3.5wt.\% $\mathrm{NaCl}$ solution at room temperature to determine the corrosion behaviour of the solution-treated samples. Corrosion tests were 
carried out by Ivium Compactstat potentiostat at a scanning rate of $1 \mathrm{mV} \cdot \mathrm{s}^{-1}$. Prior to each experiment, solution-treated samples were polished with $1 \mu \mathrm{m}$ diamond paste, washed with distilled water, cleaned with acetone and dried by warm flowing air. Each corrosion test was applied on $1 \mathrm{~cm}^{2}$ surface area. An electrochemical cell consisted of the working electrode (G-NiCr28W), reference electrode ( $\mathrm{Ag} / \mathrm{AgCl}$ electrode) and counter electrode (platinum plate). The surface area ratio of the counter electrode to the working electrode was equal to 4 .

The effect of morphological changes on the hardness was examined using a Vickers hardness test with $\mathrm{HV}_{0.3}$. For each sample, 5 hardness tests were performed and the average hardness values were given with deviations.

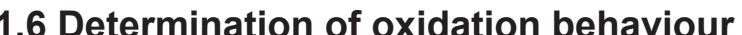

Solution treatments were applied at atmospheric conditions. The samples were weighed prior to and following the solution treatment processes in order to determine the oxidation behaviour during the solution treatment. Increase in the mass was multiplied with 2.6 and thus, the loss in mass of the metal was determined ${ }^{[20]}$.

\section{Results and discussion}

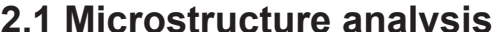

Microstructures of the solution-treated samples taken by $\mathrm{OM}$ were given in Fig. 1. The microstructure of the solution-treated samples consisted of the FCC matrix and carbide structures in particular. Fine dispersed intragranular carbides existed with grain boundary eutectic carbides (primary carbide) in the microstructure of samples solution treated at $1,040{ }^{\circ} \mathrm{C}$, especially for $\mathrm{S} 1$ as shown in Fig. 1(a). The primary carbides displayed a tendency to grow and also, coarse grain boundary carbides were obtained, while the intragranular carbides were dissolving in the matrix structure.
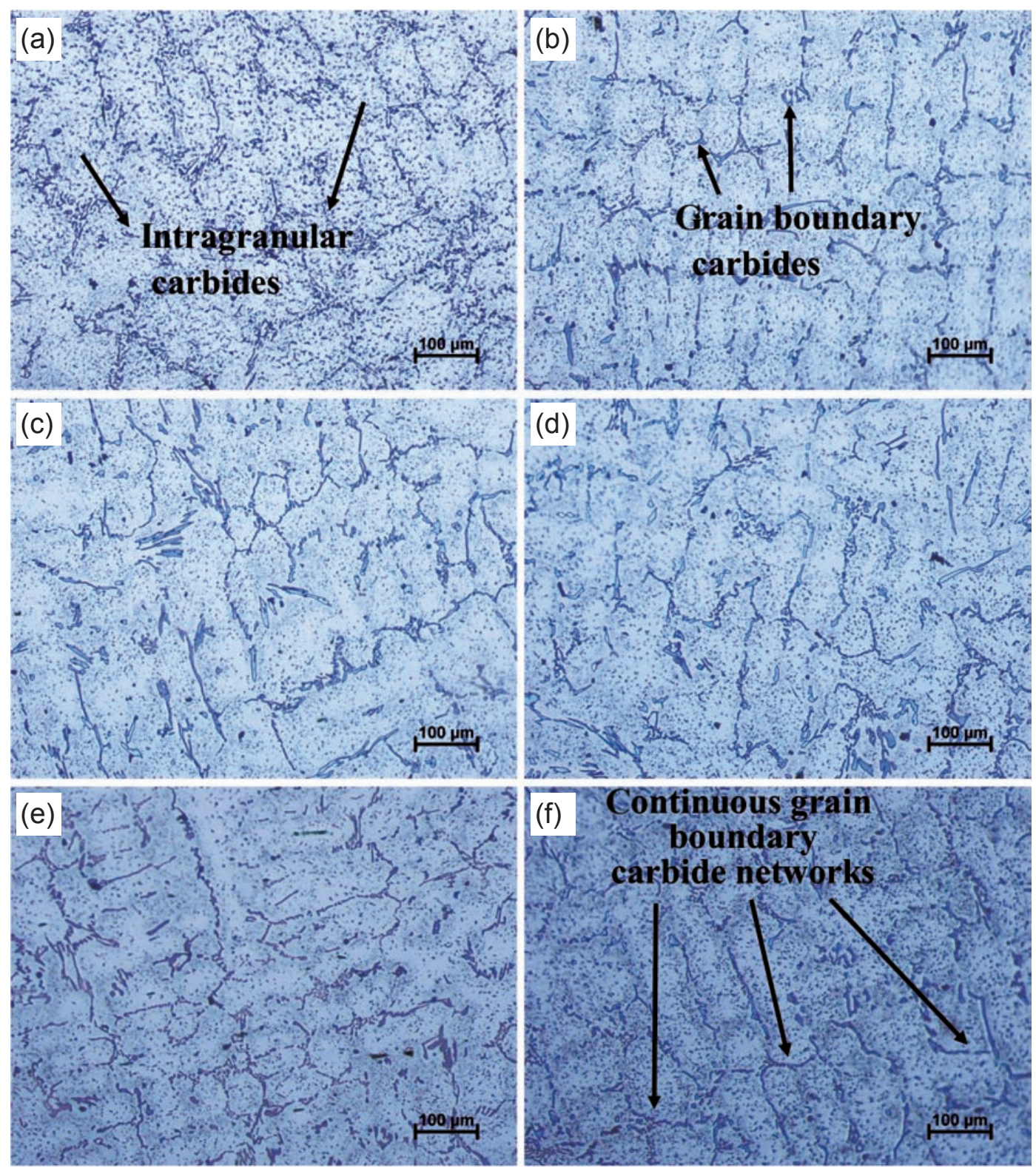

Fig. 1: Microstructures of solution-treated samples taken by OM: (a) $1,040{ }^{\circ} \mathrm{C}$ for $1 \mathrm{~h}$ (S1), (b) $1,040{ }^{\circ} \mathrm{C}$ for $8 \mathrm{~h}$ (S2), (c) $1,100{ }^{\circ} \mathrm{C}$ for $1 \mathrm{~h} \mathrm{(S3),} \mathrm{(d)} 1,100{ }^{\circ} \mathrm{C}$ for $8 \mathrm{~h}$ (S4), (e) $1,160{ }^{\circ} \mathrm{C}$ for $1 \mathrm{~h}$ (S5), (f) $1,160{ }^{\circ} \mathrm{C}$ for $8 \mathrm{~h}$ (S6) 
Coalescence of the primary carbides was observed at grain boundaries and continuous primary carbide networks were formed with the increasing solution treatment temperature. It was clearly seen that continuous primary carbide networks formed in the microstructure of S4. Moreover, primary carbide networks were quite evident for S6 which was solution-treated at $1,160{ }^{\circ} \mathrm{C}$ for $8 \mathrm{~h}$. Solution treatment was applied to refine the microstructure of the G-NiCr28W alloy. Due to the application of solution treatment at higher temperatures, chromiumiron based carbides transformed into tungsten-molybdenumchromium-iron based carbides. In addition, the grain boundary carbides tend to be coarsened ${ }^{[26]}$

Figure 2 shows the morphologies of the carbides formed in the NAs. $\mathrm{MC}, \mathrm{M}_{7} \mathrm{C}_{3}, \mathrm{M}_{6} \mathrm{C}$ and $\mathrm{M}_{23} \mathrm{C}_{6}$ are the typical carbide structures that occurred depending on the chemical composition of the NAs. $\mathrm{M}_{23} \mathrm{C}_{6}$ type carbides have discontinuous blocky, plate, and cellular morphologies and generally, " $\mathrm{M}$ " refers to the chromium based structure. $\mathrm{MC}$ and $\mathrm{M}_{6} \mathrm{C}$ type carbides are more stable with respect to $\mathrm{M}_{23} \mathrm{C}_{6}$, and formation temperatures are also higher. For $\mathrm{MC}$ and $\mathrm{M}_{6} \mathrm{C}$ type carbides, "M" refers to tungsten, vanadium and titanium depending on chemical composition and iron can also exist for low amounts in the carbide structure together with these alloying elements ${ }^{[7,27-29]}$.

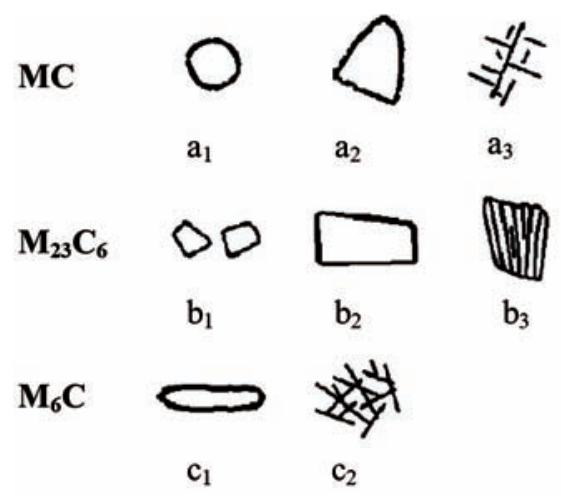

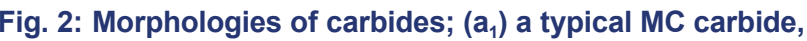

$\square$ ) blocky and (a) script MC morphologies,

$\square$ ) discontinuous blocky, (b) plate and (b)

C type carbides, (c) blocky and (c)

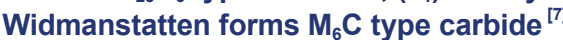

SEM micrographs of S1, S4 and S6 are given in Fig. 3. Morphologies of the carbides formed in the solution-treated samples were classified according to Fig. 2. S1 and S4 consisted of grain boundary carbides, discontinuous blocky carbides (square shaped) and rod-like shaped carbides (rectangular shaped), distributed in the matrix structure. Also, S6 comprised of blocky type carbide together with other phases existing in the S1 and S4. Discontinuous blocky and rod-like shaped carbides grew into larger particulates with increasing solution treatment temperature and time. Furthermore, blocky type carbide was found at elevated solution treatment temperature due to the occurrence of elemental diffusion at higher rates. Also, some carbides dislodged during the grinding and etching steps of the metallographic preparation as shown in Fig. 3(b) and 3(c).

EDS analysis of the spots given in Fig. 3 could be seen in
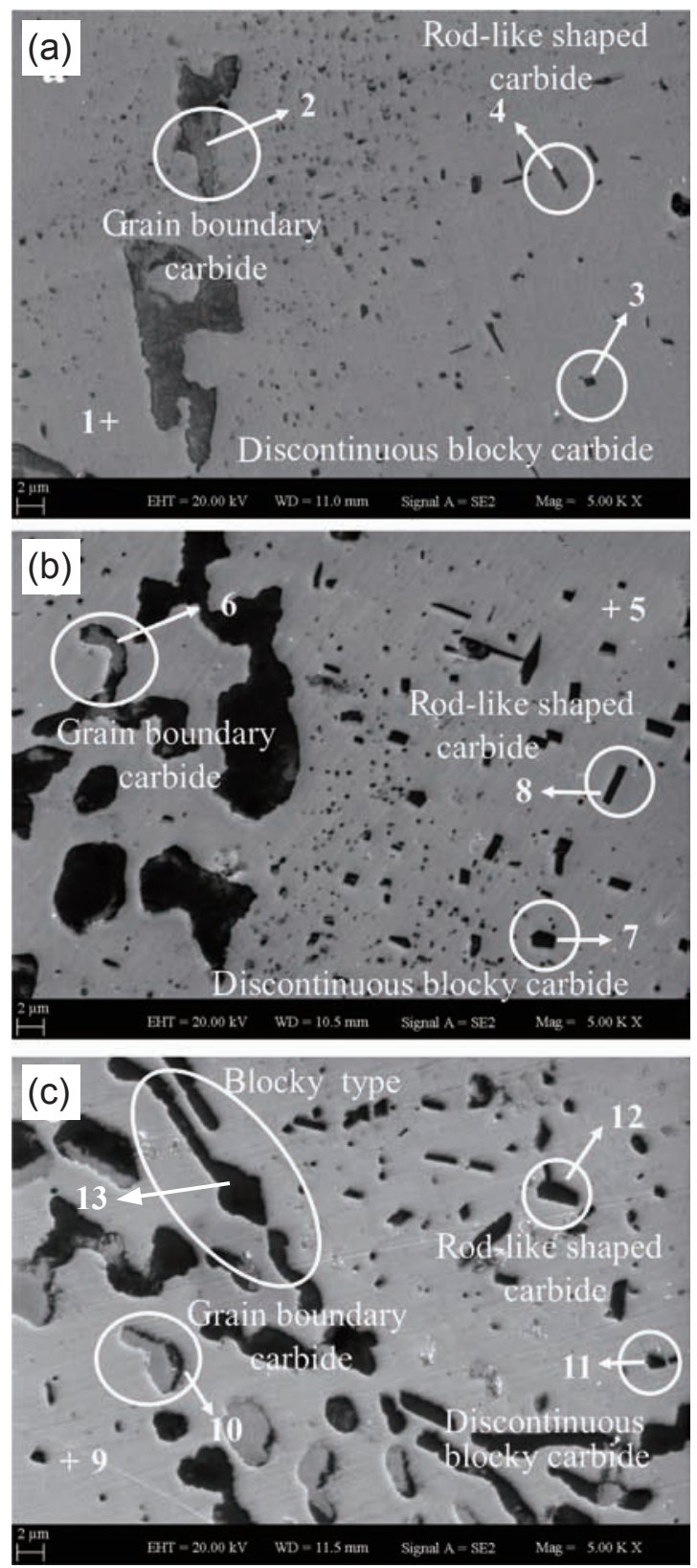

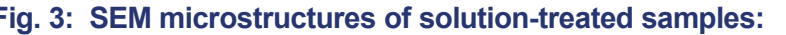

(a) $1,040{ }^{\circ} \mathrm{C}$ for $1 \mathrm{~h}$ (S1), (b) $1,100{ }^{\circ} \mathrm{C}$ for $8 \mathrm{~h}$ (S4),

(c) $1,160{ }^{\circ} \mathrm{C}$ for $8 \mathrm{~h}$ (S6)

Table 2. Oxygen was determined in all samples due to the application of the solution treatment processes at atmospheric conditions. Matrix structures of S1, S4 and S6 were a nickel rich phase, and the matrix phase contained tungsten in S1. However, the amount of the carbide forming elements (chromium and tungsten) in the matrix structure decreased from S1 to S6. Grain boundary carbides were chromium based carbides and tungsten content of the grain boundary carbides was increased by the solution treatment process applied at 1,160 ${ }^{\circ} \mathrm{C}$ for $8 \mathrm{~h}$. In particular, dissolution of intragranular carbides and reduction of carbide forming elements proportion in the matrix structure led to the formation of tungsten enriched grain boundary carbide. Discontinuous blocky and rod-like shaped carbides were nickel rich carbides with a small amount of chromium and tungsten. There was no significant change in the 
Table 2: EDS analysis of spots given in Fig. 3 (wt.\%)

\begin{tabular}{|c|c|c|c|c|c|c|c|c|}
\hline \multicolumn{9}{|c|}{ Matrix structure } \\
\hline 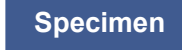 & 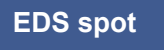 & $\square$ & Cr & $\square$ & $\square \square$ & $\square \square$ & $\square \square$ & $\square \square$ \\
\hline $\mathrm{S} 1$ & 1 & 0.82 & 24.34 & 4.43 & 18.26 & 0.96 & 1.81 & 49.38 \\
\hline S4 & 5 & 0.91 & 23.28 & - & 18.45 & 1.09 & 2.20 & 54.07 \\
\hline S6 & 9 & 0.93 & 22.41 & - & 18.39 & 0.88 & 2.22 & 55.17 \\
\hline \multicolumn{9}{|c|}{ Grain boundary carbides } \\
\hline 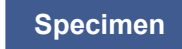 & 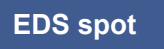 & C & $\square$ & $\mathrm{Cr}$ & ૧० & $\square \square$ & $\square$ & $\square \square$ \\
\hline $\mathrm{S} 1$ & 2 & 2.10 & 2.14 & 76.74 & 1.84 & 5.26 & 6.22 & 5.70 \\
\hline S4 & 6 & 1.51 & 1.54 & 74.94 & 1.40 & 7.79 & 8.74 & 4.08 \\
\hline S6 & 10 & 1.17 & 1.51 & 71.49 & 1.87 & 5.91 & 11.26 & 6.79 \\
\hline \multicolumn{9}{|c|}{ Discontinuous blocky carbides } \\
\hline 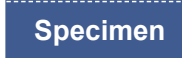 & 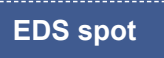 & C & $\square$ & $\mathrm{Cr}$ & $\square \square$ & $\square \square$ & $\square$ & $\square \square$ \\
\hline S1 & 3 & 1.05 & 1.06 & 23.63 & 1.12 & 17.06 & 5.51 & 50.57 \\
\hline $\mathrm{S} 4$ & 7 & 1.28 & 2.16 & 23.13 & 1.01 & 13.43 & 8.50 & 50.49 \\
\hline S6 & 11 & 1.38 & 0.95 & 23.83 & 1.23 & 12.91 & 9.24 & 50.46 \\
\hline \multicolumn{9}{|c|}{ Rod-like shaped carbides } \\
\hline 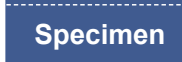 & 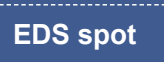 & C & $\square$ & $\mathrm{Cr}$ & $\square \square$ & $\square \square$ & $\square$ & $\square \square$ \\
\hline $\mathrm{S} 1$ & 4 & 1.08 & 0.88 & 24.30 & 0.75 & 18.11 & 3.77 & 51.11 \\
\hline S4 & 8 & 1.33 & 2.17 & 42.75 & 0.82 & 13.51 & 8.71 & 30.71 \\
\hline S6 & 12 & 1.81 & 1.86 & 59.18 & 0.93 & 8.90 & 10.37 & 16.95 \\
\hline \multicolumn{9}{|c|}{ Blocky type carbide } \\
\hline Specimen & EDS spot & C & 0 & $\mathrm{Cr}$ & $\mathrm{Mn}$ & $\mathrm{Fe}$ & W & $\mathrm{Ni}$ \\
\hline S6 & 13 & 2.57 & 2.36 & 69.92 & 0.72 & 8.63 & 11.83 & 3.97 \\
\hline
\end{tabular}

chemical composition of discontinuous blocky carbides despite a small increase in the tungsten ratio. However, according to the EDS analysis of rod-shaped like carbides, it can be seen that the chromium and tungsten ratio was increased at the elevated solution treatment temperature due to the diffusion of carbide forming elements. S6 was different from other samples with the formation of blocky type carbide. Blocky type carbide was different in terms of elemental composition from the discontinuous blocky and the rod-like shaped carbides, while it was different in terms of shape and larger grain size from the grain boundary carbides. Blocky carbides occurred at grain boundaries of S6 and diffusion of carbide forming elements from the matrix was quite effective for the nucleation and growth of these types of carbides at grain boundaries. Thus, the high temperature process $\left(1,160{ }^{\circ} \mathrm{C}\right.$ for $\left.8 \mathrm{~h}\right)$ caused the formation of blocky carbides, which were enriched in terms of chromium and tungsten, with induced high diffusion rates.

XRD analysis of the solution-treated samples can be seen in Fig. 4. According to Fig. 4, the samples, that were solution treated at $1,040{ }^{\circ} \mathrm{C}$ and $1,100{ }^{\circ} \mathrm{C}$, consisted of nickel-based matrix together with $\mathrm{Cr}_{7} \mathrm{C}_{3}$ and $\mathrm{Cr}_{23} \mathrm{C}_{6}$ carbides. As mentioned in Table 2, the carbides formed in $\mathrm{S} 1$ were chromium rich carbides and obtained EDS results were compatible with XRD analysis. Chromium rich carbides preserved their structure during the solution treatment process at $1,040{ }^{\circ} \mathrm{C}$ or $1,100{ }^{\circ} \mathrm{C}$, and for this reason, $\mathrm{S} 1, \mathrm{~S} 2, \mathrm{~S} 3$ and $\mathrm{S} 4$ comprised of typical $\mathrm{M}_{7} \mathrm{C}_{3}$ and $\mathrm{M}_{23} \mathrm{C}_{6}$ carbides. Also, S5 and S6, that were solution treated at $1,160{ }^{\circ} \mathrm{C}$ for $1 \mathrm{~h}$ or $8 \mathrm{~h}$, contained $\mathrm{Cr}_{7} \mathrm{C}_{3}, \mathrm{Cr}_{23} \mathrm{C}_{6}$, $\mathrm{Fe}_{2} \mathrm{~W}_{2} \mathrm{C}$ carbides together with nickel rich matrix. According to EDS analysis given in Table 2, carbide forming elements in the matrix structure decreased due to elevated solution treatment temperature and time. Therefore, chromium and tungsten content of the matrix structure formed in S6 was lower than other heat-treated samples. Consequently, S6 included blocky type carbides besides grain boundary carbides, discontinuous blocky carbides and rod-like shaped carbides, as seen in Fig. 3(c). These blocky type carbides were tungsten rich carbides like the grain boundary carbides that occurred in S6. Consequently, solution treatment processes applied at $1,160{ }^{\circ} \mathrm{C}$ induced an enrichment of grain boundary carbides in terms of tungsten. As a result, tungsten and iron-based $\mathrm{Fe}_{2} \mathrm{~W}_{2} \mathrm{C}$ carbide structures occurred in S5 and S6. Ultimately $\mathrm{M}_{7} \mathrm{C}_{3}$ and $\mathrm{M}_{23} \mathrm{C}_{6}$ type carbides started to transform into a more stable carbide structure with increasing solution treatment temperature and time. 

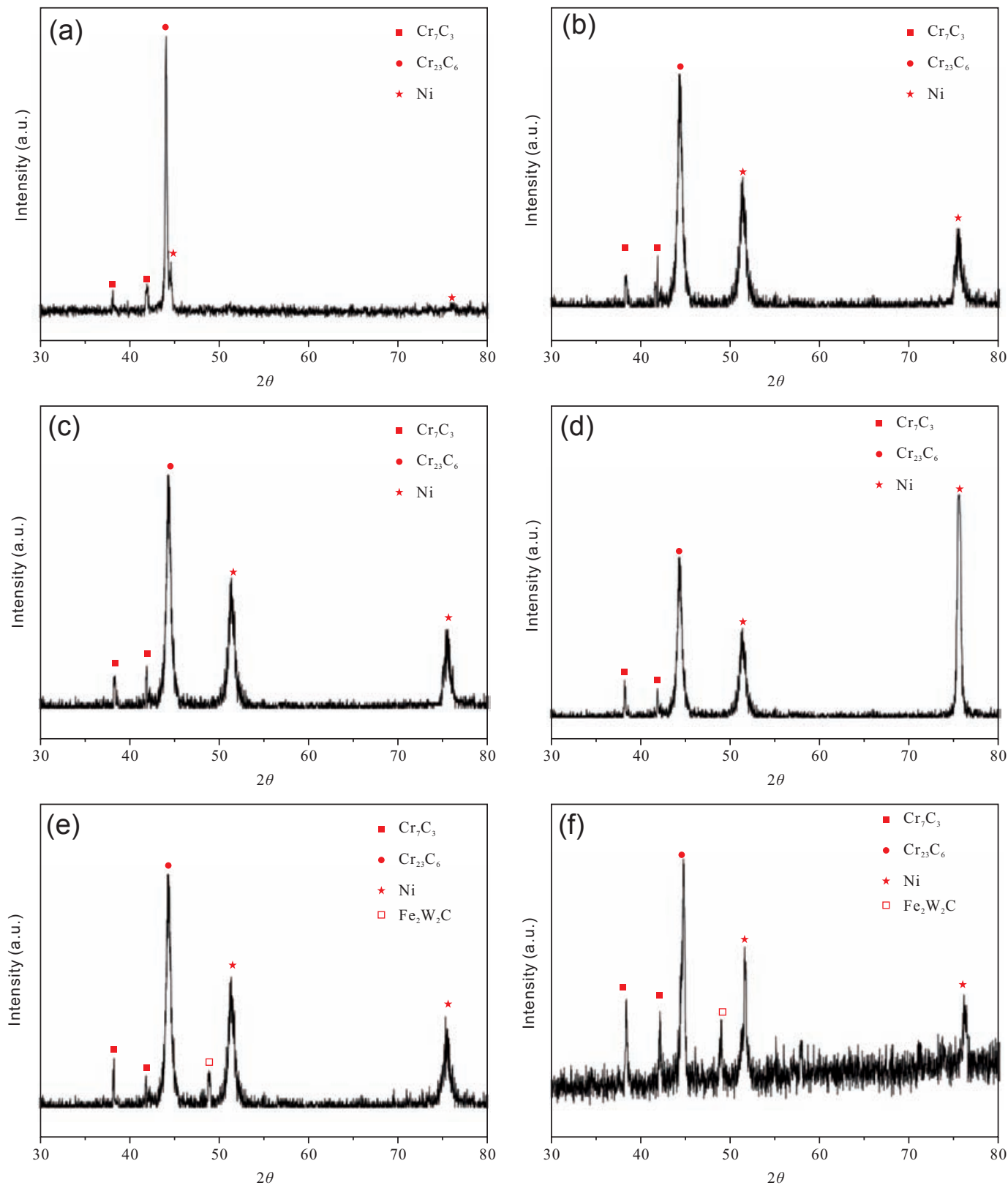

Fig. 4: XRD results of samples: (a) $1,040{ }^{\circ} \mathrm{C}$ for $1 \mathrm{~h}$ (S1), (b) $1,040{ }^{\circ} \mathrm{C}$ for $8 \mathrm{~h}$ (S2), (c) $1,100{ }^{\circ} \mathrm{C}$ for $1 \mathrm{~h}(\mathrm{~S} 3)$, (d) $1100^{\circ} \mathrm{C}$ for $8 \mathrm{~h}(\mathrm{~S} 4),(\mathrm{e}) 1,160^{\circ} \mathrm{C}$ for $1 \mathrm{~h}$ (S5), (f) $1,160{ }^{\circ} \mathrm{C}$ for $8 \mathrm{~h}$ (S6)

\subsection{Hardness, oxidation and potentiodynamic}

Figure 5 shows hardness of the solution-treated samples. Average hardness values of S1 and S6 were $216.92 \mathrm{HV}$ and $254.87 \mathrm{HV}$, respectively. Average hardness values increased with the solution treatment temperature and time. Also as shown in Fig. 5, solution treatment processes applied at $1,160{ }^{\circ} \mathrm{C}$ for 1 $\mathrm{h}$ and $8 \mathrm{~h}$ led to a significant increase in hardness values due to the formation of $\mathrm{Fe}_{2} \mathrm{~W}_{2} \mathrm{C}$ carbide. The increase in hardness for solution-treated samples was related to the growth of intragranular carbides (discontinuous blocky and rod-like shaped carbides) and enrichment of grain boundary carbides in terms of tungsten. In particular for S5 and S6, the formation of $\mathrm{Fe}_{2} \mathrm{~W}_{2} \mathrm{C}$ blocky type carbide at grain boundaries provided the highest hardness values among the solution-treated samples.

Oxidation behaviour of the solution-treated samples was

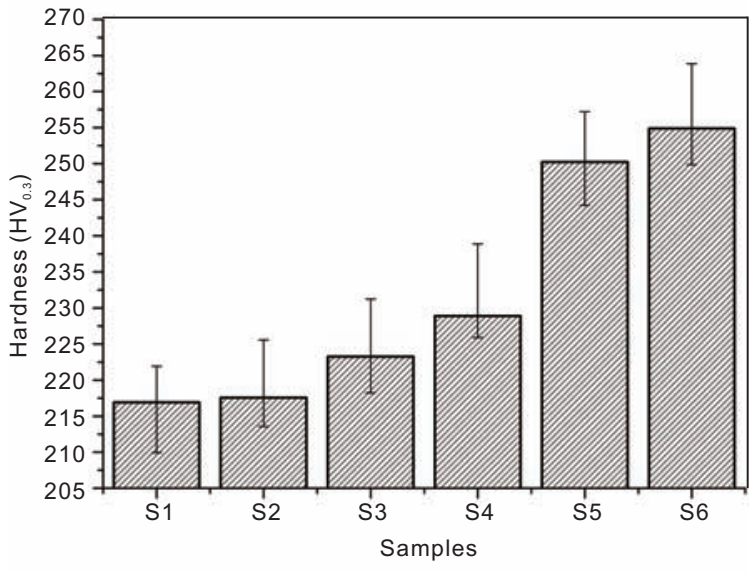

Fig. 5: Hardness (HV) of solution-treated samples:

(a) $1,040{ }^{\circ} \mathrm{C}$ for $1 \mathrm{~h}$ (S1), (b) $1,040^{\circ} \mathrm{C}$ for $8 \mathrm{~h}$ (S2),

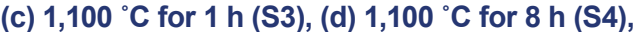

(e) $1,160{ }^{\circ} \mathrm{C}$ for $1 \mathrm{~h}$ (S5), (f) $1,160{ }^{\circ} \mathrm{C}$ for $8 \mathrm{~h}$ (S6) 
determined by measuring the weight gain of samples during the solution treatment processes. The oxidized metal weight values are given in Fig. 6. Oxidized metal weight increases with the increasing solution treatment temperature and time, due to a diffusion-based character of the oxidation phenomenon. Solution treatment processes applied at $1,040{ }^{\circ} \mathrm{C}$ and $1,100{ }^{\circ} \mathrm{C}$ induced similar oxidation effect for the samples. Particularly, oxidation occurring at $1,160{ }^{\circ} \mathrm{C}$ was excessive and the oxidized metal weight was greater for S5 and S6. For that matter, the solution treatment process should be applied below $1,160{ }^{\circ} \mathrm{C}$ in order to prevent excessive oxidation of G-NiCr28W alloy.

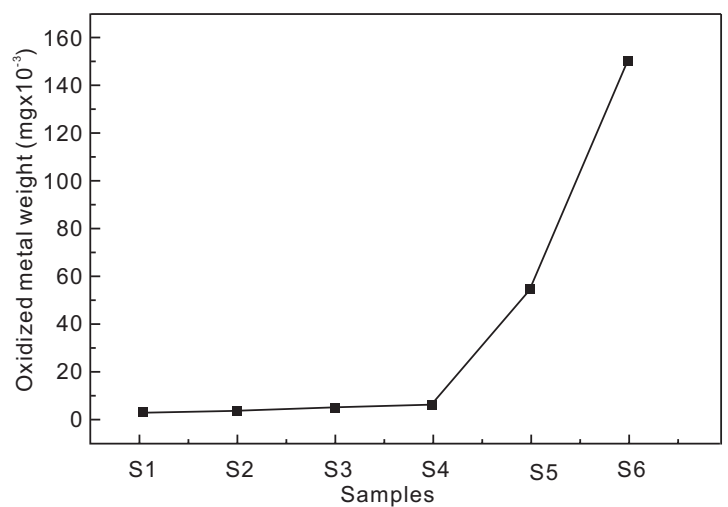

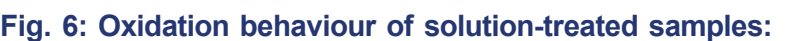
$1,040{ }^{\circ} \mathrm{C}$ for $1 \mathrm{~h}(\mathrm{~S} 1), 1,040{ }^{\circ} \mathrm{C}$ for $8 \mathrm{~h}$ (S2), $1,100{ }^{\circ} \mathrm{C}$ for $1 \mathrm{~h}(\mathrm{~S} 3), 1,100{ }^{\circ} \mathrm{C}$ for $8 \mathrm{~h}$ (S4), $1,160{ }^{\circ} \mathrm{C}$ for $1 \mathrm{~h}$ (S5), $1,160^{\circ} \mathrm{C}$ for $8 \mathrm{~h}(\mathrm{~S} 6)$

The potentiodynamic polarization curves of the solutiontreated samples S1, S4 and S6 are given in Fig. 7. Polarization curves demonstrate none of the samples displayed the passivation behaviour. The shape of the potentiodynamic polarization curves indicated that all samples exhibited active dissolution behaviour due to the occurrence of a steady increase in the anodic current density when the potential shifts in the noble direction. Moreover, all samples exhibited an active dissolution near the $E_{\text {corr }}$ because of the existence of intergranular and intergranular carbides. As mentioned in the microstructure analysis, all solution-treated samples consisted of nickel-based matrix and chromium rich carbides. This induced an electrochemical potential difference between the matrix and carbides. Even more, enrichment of carbides in terms of chromium and tungsten led to the formation of chromium and tungsten depleted zones around their own structures. Hence, the vicinity of the carbide structure acts as an anode, while the carbide structure acts as a cathode, and dissolution was observed near the corrosion potential values during the potentiodynamic polarization test of the S1, S4 and S6.

Experimental results of the potentiodynamic polarization tests were given in Table 3. $E_{\text {corr }}$ indicates the corrosion resistance of the samples and $I_{\text {corr }}$ represents kinetics and dynamic trends of the chemical reactions during the electrochemical corrosion. $E_{\text {corr }}$ value decreased with increasing solution treatment temperature, while $I_{\text {corr }}$ value increased. It was deduced from the results that the corrosion tendency and the corrosion kinetics of the samples were enhanced by the formation of carbides and the chromium/

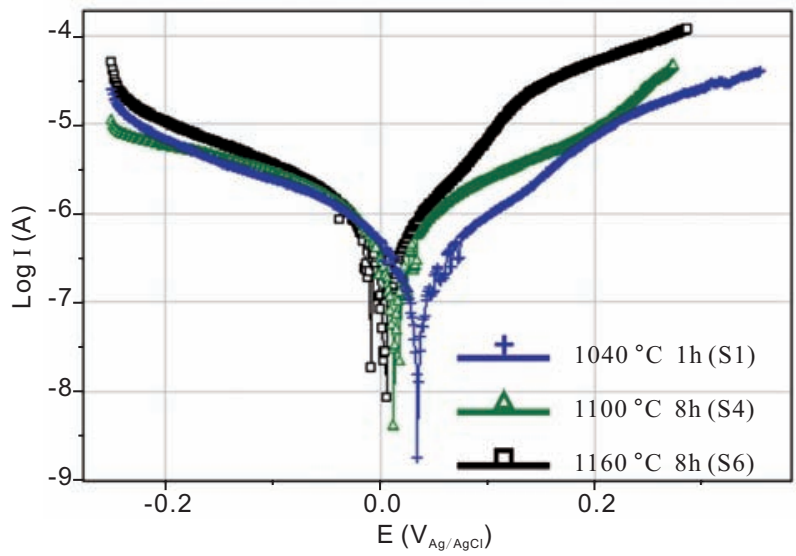

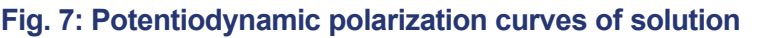
treated samples: S1, S4 and S6

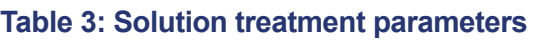

\begin{tabular}{cccc}
$E_{(V)}$ & $\boldsymbol{i}$ & Corrosion rate \\
$\mathrm{S} 1$ & 0.0376 & 1.1160 & 1.1400 \\
$\mathrm{~S} 4$ & 0.0117 & 3.0350 & 3.1000 \\
$\mathrm{~S} 6$ & 0.0070 & 5.5800 & 5.7100 \\
\hline
\end{tabular}

tungsten depleted matrix structure. Accordingly, the corrosion rate of the samples was increased by the increasing solution treatment temperature. Moreover, the formation of $\mathrm{Fe}_{2} \mathrm{~W}_{2} \mathrm{C}$ blocky carbides and chromium/tungsten depleted zones resulted in a five times higher corrosion rate in S6 than in S1.

\section{Conclusions}

In this study, the solution treatment process was applied at $1,040{ }^{\circ} \mathrm{C}, 1,100{ }^{\circ} \mathrm{C}$ and $1,160{ }^{\circ} \mathrm{C}$ for $1 \mathrm{~h}$ and $8 \mathrm{~h}$. Microstructure, corrosion and oxidation properties depending on the solution treatment process parameters were examined, and the following conclusions were obtained.

(1) The solution-treated samples consisted of intragranular carbides together with chromium rich grain boundary carbides. Carbide structures enrich in terms of tungsten at elevated temperatures for investigated samples. In particular, $\mathrm{Fe}_{2} \mathrm{~W}_{2} \mathrm{C}$ type carbide forms during the solution treatment process at $1,160{ }^{\circ} \mathrm{C}$.

(2) Metal loss values due to oxidation during the solution treatment process increase with the increasing solution treatment temperature. The oxidation process is a diffusion-based process, thus the excessive metal loss occurs at elevated treatment temperatures.

(3) Corrosion behaviour of the samples is affected by the physical and chemical variations of the carbides. The sample solution-treated at $1,160{ }^{\circ} \mathrm{C}$ for $8 \mathrm{~h}$ exhibits the lowest corrosion resistance due to the formation of the blocky carbides. The blocky carbides accelerate the corrosion rate in $3.5 \mathrm{wt} . \% \mathrm{NaCl}$ media.

(4) Hardness of the samples solution-treated at $1,160{ }^{\circ} \mathrm{C}$ increases significantly by the formation of blocky type $\mathrm{Fe}_{2} \mathrm{~W}_{2} \mathrm{C}$ carbides. 
In conclusion, it was determined from experimental researches that in order to provide desirable microstructure, corrosion and mechanical properties, the solution treatment of the G-NiCr28W alloy should not be applied above $1,100{ }^{\circ} \mathrm{C}$.

\section{References}

[1] Dortlew A, Garbiak M, Piekarski B. Cast steels for creepresistant parts used in heat treatment plants. Archives of Foundry Engineering, 2012, 12(4): 31-38.

[2] Piekarski B, Drotlew A. Cast construction elements for heat treatment furnaces. Archives of Foundry Engineering, 2011, 11(3): 163-170.

[3] Piekarski B, Drotlew A. Cast functional accessories for heat treatment furnaces. Archives of Foundry Engineering, 2010, 10(4): 183-190.

[4] Shi S, Lippold J C. Microstructure evolution during service exposure of two cast, heat resisting stainless steels - HP-Nb modified and 20-32Nb. Materials Characterization, 2008, 59(8): 1029-1040.

[5] Davis J R. Heat resistant materials. Ohio: ASM International, 1997.

[6] Pirowski Z, Wodnicki J, Gwizdz A. Nitrogen hardening of creepresistant G-NiCr28W alloy. Archives of Foundry Engineering, 2010, 10(3): 79-84.

[7] Sukhdeep Singh Handa. Precipitation of Carbides in a $\mathrm{Ni}$ based Superalloy. MSc. Thesis. Rosemead: University of West, Rosemead, 2014: 8.

[8] Lvov G, Levit G I, Kaufman M J. Mechanism of primary MC carbide decomposition in Ni-base superalloys. Metallurgical and Materials Transactions A, 2014, 35(6): 1669-1679.

[9] Qin X Z, Guo J T. Precipitation and thermal instability of $\mathrm{M}_{23} \mathrm{C}_{6}$ carbide in cast Ni-base superalloys $\mathrm{K} 452$. Materials Letters, 2008, 62(2): 258-261.

[10] Hwang S S, Lim Y S, Kim W S, et al. Role of grain boundary carbides in cracking behavior of $\mathrm{Ni}$ base alloys. Nuclear Engineering and Technology, 2013, 45(1): 73-80.

[11] Qin X Z, Guo J T, Yuan C, et al. Decomposition of primary MC carbide and its effects on the fracture behaviors of a cast $\mathrm{Ni}$ base superalloy. Materials Science and Engineering A, 2008, 485(1-2): 74-79.

[12] Lee H J, Kim H, Kim D, et al. Microstructure evolution of a $\mathrm{Ni}$ Cr-W superalloy during long term-aging at high temperatures. Materials Characterization, 2015, 106: 283-291.

[13] He L Z, Zheng Q, Sun X F, et al. $\mathrm{M}_{23} \mathrm{C}_{6}$ precipitation in a Ni-base superalloy M963. Journal of Materials Science, 2005, 40(11): 2959-2964.
[14] Bai G, Li J, Hu R, et al. Effect of thermal exposure on the stability of carbides in Ni-Cr-W based superalloy. Materials Science and Engineering A, 2011, 528(26): 2339-2344.

[15] Li Y, Gao Y, Fan Z. First-principles study on the stability and mechanical property of eta $\mathrm{M}_{2} \mathrm{~W}_{3} \mathrm{C}(\mathrm{M}=\mathrm{Fe}, \mathrm{Co}, \mathrm{Ni})$ compounds. Physica B, 2010, 405(3): 1011-1017.

[16] Zengwu $\mathrm{T}$, Jinshan $\mathrm{L}$, Rui $\mathrm{H}$, et al. Effects of solution heat treatment on carbide of $\mathrm{Ni}-\mathrm{Cr}-\mathrm{W}$ superalloy. Rare Metal Materials and Engineering, 2010, 39(7): 1157-1161.

[17] Rodriquez J, Haro S, Velasco A, et al. Aging of cast Ni-base heat resistant alloy. International Journal of Cast Metals Research, 2004, 17(3): 188-192.

[18] Sun W, Qin X, Guo J, et al. Thermal stability of primary MC carbide and its influence on the performance of cast Ni-base superalloys. Materials and Design, 2015, 69: 81-88.

[19] Haugsrud R. On the high-temperature oxidation of nickel. Corrosion Science, 2003, 45(1): 211-235.

[20] Svistunova T V, Kozlova N N, Shevakin A F, et al. Effect of iron and carbon on the structure and properties of chromium-nickle alloy. Metal Science and Heat Treatment, 2015, 57(7-8): 379-385.

[21] Perez-Gonzalez F A, Ramirez-Ramirez J H, Terock M, et al. High-temperature oxidation of a nickel base superalloy at different oxygen partial pressures. Corrosion Engineering, Science and Technology, 2016, 51(7): 513-521.

[22] Zhang T B, Dong R F, Hu R, et al. Hot corrosion characteristics of $\mathrm{Ni}-20 \mathrm{Cr}-18 \mathrm{~W}$ superalloy in molten salt. Transactions of Nonferrous Metals Society of China, 2015, 25(11): 3840-3846.

[23] Silva F J G, Santos J, Gouveia R. Dissolution of grain boundary carbides by the effect of solution annealing heat treatment and aging treatment on heat-resistant cast steel HK30. Metals, 2017, 7(7): 251.

[24] Sourmail T. Precipitation in creep resistant austenitic stainless steels. Materials Science and Technology, 2001, 17(1): 1-14.

[25] Ha V T, Jung W S. Effects of heat treatment processes on microstructure and creep properties of a high nitrogen $15 \mathrm{Cr}$ $15 \mathrm{Ni}$ austenitic heat resistant stainless steel. Materials Science and Engineering A, 2011, 528(24): 7115-7123.

[26] Toth L. Transition metal carbides and nitrides. London: Academic Press, 1971.

[27] Oyama S T. The chemistry of transition metal carbides and nitrides. Dordrecht: Springer, 1996.

[28] Jiang $L$, Hu R, Kou H, et al. The effect of $\mathrm{M}_{23} \mathrm{C}_{6}$ carbides on the formation of grain boundary serrations in a wrought $\mathrm{Ni}$-based superalloy. Materials Science and Engineering A, 2012, 536 37-44.

[29] Hu R, Bai G, Li J, et al. Precipitation behavior of grain boundary $\mathrm{M}_{23} \mathrm{C}_{6}$ and its effect on tensile properties of $\mathrm{Ni}-\mathrm{Cr}-\mathrm{W}$ based superalloy. Materials Science and Engineering A, 2012, 548: 83-88. 